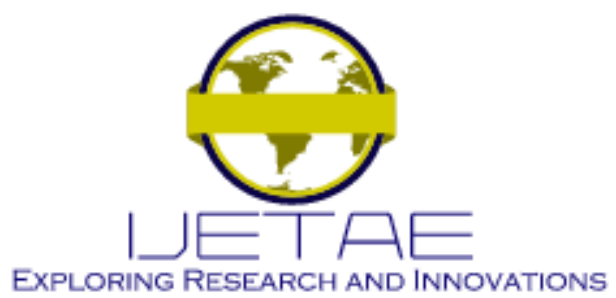

International Journal of Emerging Technology and Advanced Engineering

Website: www.ijetae.com (E-ISSN 2250-2459, Scopus Indexed, ISO 9001:2008 Certified Journal, Volume 12, Issue 01, January 2022)

Manuscript Received: 08 December 2021, Received in Revised form: 07 January 2022, Accepted: 12 January 2022

DOI: $10.46338 /$ ijetae0122_19

\title{
Vertical Handover Decision Making Algorithms for 5G Heterogeneous Networks: A Review
}

\author{
Mark Irwin Goh ${ }^{1}$, Hoe Tung $\mathrm{Yew}^{2}$, Diong Boh Wen ${ }^{3}$, Aroland M. J. Kiring ${ }^{4}$, Chung Seng Kheau \\ 1,2,3,4,5 Faculty of Engineering, Universiti Malaysia Sabah, Kota Kinabalu, Malaysia
}

\begin{abstract}
The wireless networks have been rapidly used in our daily lives, especially mobile wireless networks. An environment consisting of several networks such as WLAN, 4G-LTE, and 5G, is known as a heterogeneous network. Wireless networks are widely used to support various data services such as live video streaming, upload data, download data and cloud service depending upon their capacity and nature. When the mobile terminal is moving, the network availability will be changed. Therefore, the mobile terminal must perform handover from one network to another network in heterogeneous networks to maintain the call and quality of service $(\mathrm{QoS})$. This process is known as Vertical Handover (VHO). A seamless handover is important to provide uninterrupted high quality service while performing the handover. To achieve this, various vertical handover decision making algorithms have been proposed and studied using advanced tools and proven concepts. This paper gives an overview of current research on handover decision making in fifth generation $(5 \mathrm{G})$ heterogeneous wireless networks.
\end{abstract}

Keywords-Vertical Handover Decision Making, Heterogeneous Networks, Quality of Service, 5G, Seamless Handover

\section{INTRODUCTION}

In this fast-paced evolution era of wireless and mobile networks, seamless handover from one wireless technology to another different wireless technology is essential to guarantee the mobile terminal is always connected to the internet. A seamless handover is a process of ensuring uninterrupted service while the mobile terminal is switching from one network to another different network, such as 4G Long-Term Evolution (LTE), 5G, Wireless Fidelity (WiFi), Worldwide Interoperability for Microwave Access (WiMAX) and Universal Mobile Telecommunications System (UMTS). The handover process can be grouped into horizontal and vertical handover. A horizontal handover or intra-system handover is the process of migrating from a base station (BS) to another BS within the same network technology, such as handover between two geographically neighbouring BS of a $5 \mathrm{G}$ network.
On the other hand, vertical handover or inter-system handover is switching between two different network technologies, for example, handover from Wireless Local Area Network (WLAN) or WiFi to 5G cellular network.

The horizontal handover process is more straightforward than the vertical handover process because it only involves a single wireless network technology. A mobile terminal (MT) can choose the best base station (BS) by comparing the Received Signal Strength (RSS) from different BS. The handover is necessary if the RSS of the serving BS falls below the threshold. On the other hand, the vertical handover cannot make a handover decision based on a single RSS criterion because the RSS of different wireless technologies cannot be compared directly. The vertical handover process requires more handover criteria such as network bandwidth, power consumption, security, cost, and user preference for handover decision making.

The vertical handover can be either optional or mandatory. The handover is optional when the serving network fulfils the services requirements and other better alternative candidate networks are available. The optional handover could be performed to improve user satisfaction in terms of cost-saving, power consumption, and some other factors. Conversely, the handover is necessary when the RSS of the serving network is below the predefined RSS threshold, or network quality is incapable of meeting the service requirement and other alternative candidate networks are available. The mandatory handover decision is taken to prevent link breakdown and maintain the service quality at an acceptable level.

\section{ClassifiCATION OF HANDOVER}

Figure 1 shows the types of handovers. The horizontal handover is performed between the BS within the same wireless technology (homogeneous network) to let mobile terminals maintain the connection and service quality, such as from $5 \mathrm{G}$ BS to another $5 \mathrm{G}$ BS [1]. The vertical handover is the handover process between two different types of networks, for example, handover from WiFi to LTE. 


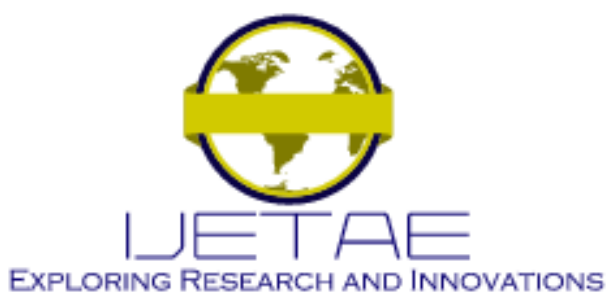

International Journal of Emerging Technology and Advanced Engineering Website: www.ijetae.com (E-ISSN 2250-2459, Scopus Indexed, ISO 9001:2008 Certified Journal, Volume 12, Issue 01, January 2022)

In the field of heterogeneous networks, vertical handover is necessary. The MT could handover to another network for a better data rate or bandwidth. Figure 2 shows the horizontal and vertical handover in the heterogeneous wireless network [2].

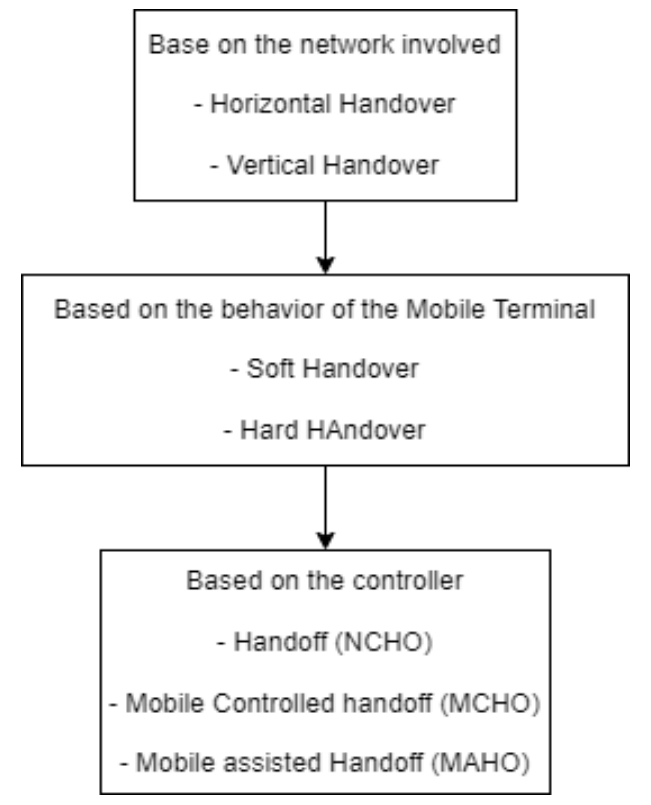

Figure 1 Types of handovers [1]

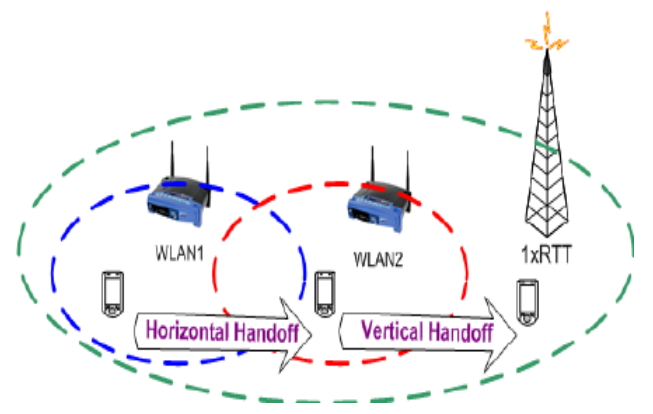

Figure 2 Vertical and horizontal handover [2]

The handover led by the mobile is often called Soft Handover. In this phase, the connection to the new network is created before disconnecting the link of the serving network. This mode is also called "make-before-break". Figure 3 shows the soft handover mechanism where the Radio Network Controller (RNC) is used to control every node that is connected to it. The RNC can perform radio resource management, mobility management and encrypts the data before sending it to the mobile [3].
Hard handover is the serving network connection break before the new network is established. This mode is also called "break before make". An interruption occurs when the MT performs the hard handover process, as shown in Figure 4.

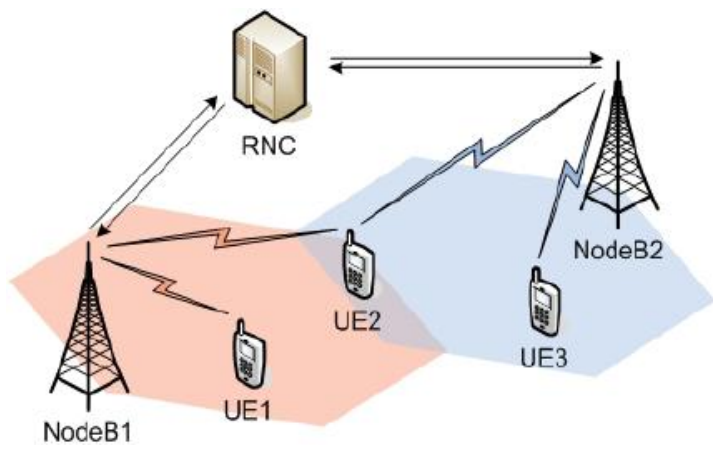

Figure 3 Soft handover Mechanism [3]

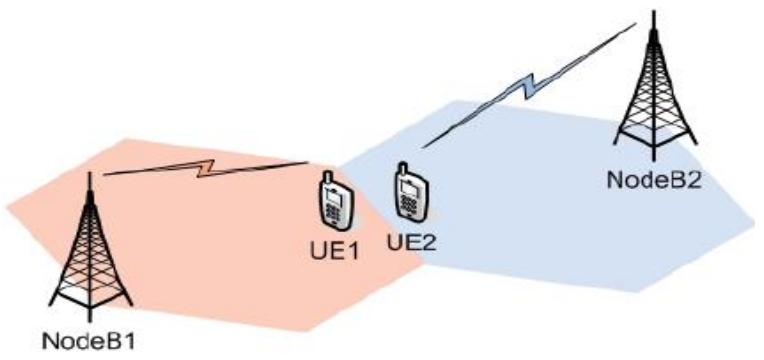

Figure 4 Hard handover Mechanism [3]

Network-controlled handoff (NCHO): The network decides whether the handover should be initiated or rejected. The mobile terminal initiates the handover. It scans for available networks and selects a new network that is considered as the best. Then the network will decide to accept or reject the handover.

Mobile-controlled handoff (MCHO): In this case, the handover is determined by the MT based on the handover criteria such as Radio Signal Strength (RSS), user preferences, mobile speed, etc. The handover would help with the service quality parameters given by the network, such as packet loss rate and bandwidth. The mobile terminal is fully in control of the handover process.

Mobile-Assisted handoff (MAHO): The network makes the handover decision based on the data provided by the mobile terminal. The mobile terminal continuously collects the network information from the neighbouring BS and sends the report to the BS for handover decision making. 


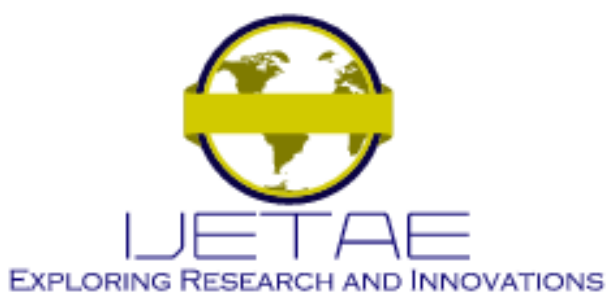

International Journal of Emerging Technology and Advanced Engineering

Website: www.ijetae.com (E-ISSN 2250-2459, Scopus Indexed, ISO 9001:2008 Certified Journal, Volume 12, Issue 01, January 2022)

\section{MEDIA INDEPENDENT HANDOVER}

The inter-network handover requires an interface between different network link-layer. Media Independent Handover Function (MIHF) located between the link layer and network layer act as an intermediate layer between upper and lower network layers. This standard can communicate with all kinds of IEEE networks. The same goes for mobile networks such as LTE, UMTS, GPRS, etc. Figure 5 shows the MIH architecture [4].

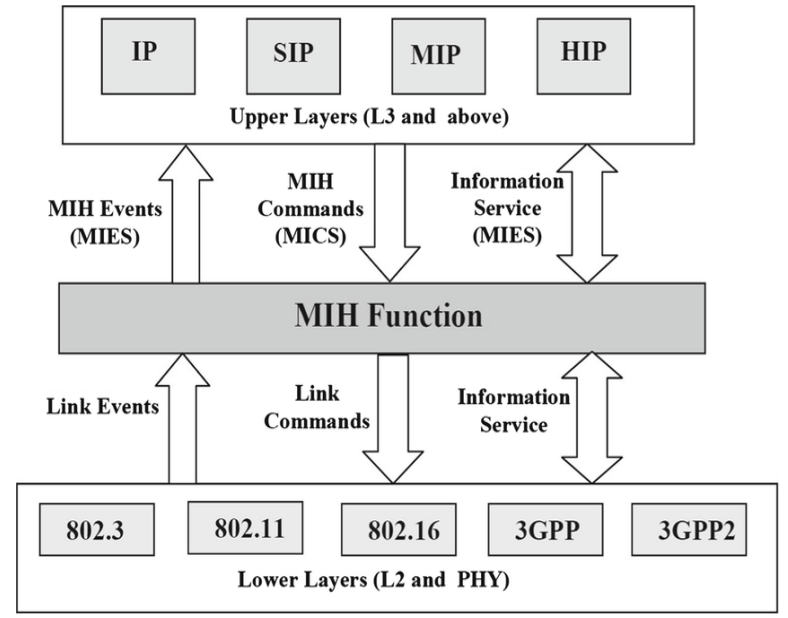

Figure 5 MIH architecture [4]

\section{Process Of Vertical Handover}

Vertical handover is an operation that allows an MT to switch from one network to another network without losing the connection. Figure 6 shows that the handover process can be categorized into three stages [1].

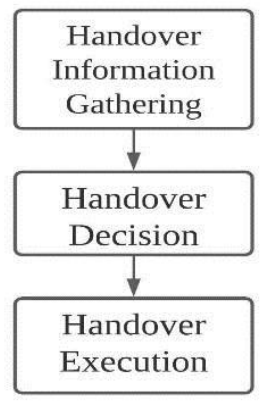

Figure 6 Handover process [1]

In the first stage, the MT scans for available networks and reads the main attributes of the available networks such as signal strength, bit error rate and level of interference.
Apart from these, MT moving speed, service requirements and terminal performance are also important criteria for handover decision making. All this information will be used in the handover decision stage.

The handover decision would be the most critical stage of the entire process. The quality of service (QoS) may be diminished by an improper handover and even disrupt the communication in progress. This phase will track the currently connected network quality and compare it with the new incoming network if it is necessary to perform the handover. The selection strategy is to choose the best network for the MT by considering user preferences, service requirements and characteristics of the available network. The last stage is to switch the network toward the targeted network. It connects to the selected network and releases the serving network.

The authentication service allows MT to roam through several access points seamlessly and safely. Figure 7 shows the handover authentication service [5]. MT registers with the server and connects to an AP to access the subscribed services. Handover authentication should be conducted at the new AP when the MT moves from the serving AP into the new AP. Through handover authentication, AP2 authenticates MT to deny any access request from an unauthorized user. A session key between the MT and AP2 should also be established to protect the data exchanged over the subsequent connection.

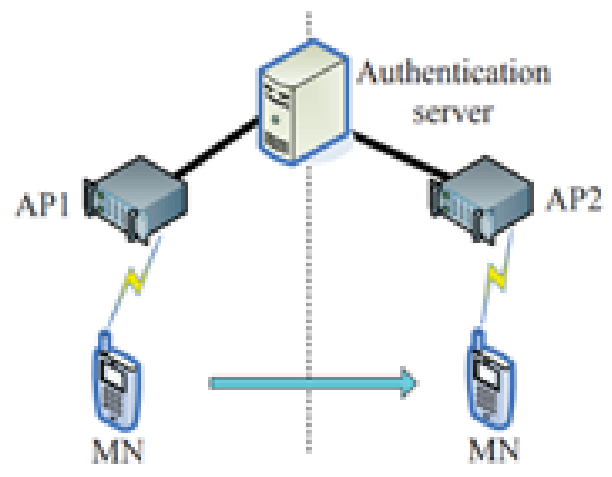

Figure 7 Handover Authentication Service [5]

\section{Vertical Handover Decision Making Criteria}

Handover parameters are the specifications that are analyzed to indicate handover necessity and choose an optimum available network. The handover judgment criteria in the network selection process can be subjective or objective to reduce or optimize nature. These criteria can be classified into four groups [6]. 


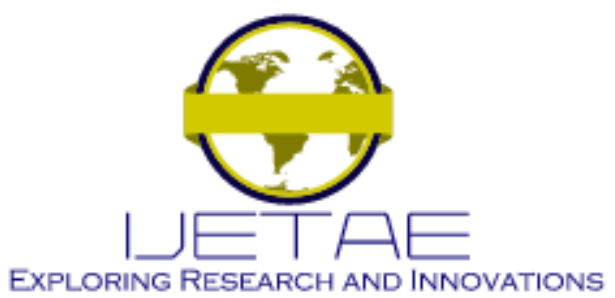

International Journal of Emerging Technology and Advanced Engineering

Website: www.ijetae.com (E-ISSN 2250-2459, Scopus Indexed, ISO 9001:2008 Certified Journal, Volume 12, Issue 01, January 2022)

\section{A. Network-related criteria}

It is the technical characteristics and efficiency of the radio access networks. These criteria are based on the network, for example, cell coverage, connection quality and capacity, throughput, load, etc.

\section{B. Terminal-related criteria}

It is related to the characteristics and current condition of the mobile terminal. For example, supported interfaces, speed, hardware performance, location-based information, energy consumption, etc.

\section{Service-related criteria}

The service requirements are closely linked with the QoS parameters like delay, jitter, error ratio, and packet loss ratio. These parameters are widely used in the QoS based handover schemes.

\section{User-related criteria}

These criteria are related to the user's expectation or satisfaction, such as the user profile and preferences, service costs, quality of experience, etc., such criteria are usually represented in linguistic terms.

\section{HANDOVER PARAMETERS}

\section{A. Received Signal Strength (RSS)}

RSS is the most selected criterion in the handover decision making. There is a close relationship between RSS readings and the distance from the MT to its point of attachment [6]. In horizontal handover, RSS represents the link quality. The higher the RSS value better the signal quality.

\section{B. Available bandwidth}

It is the most used indicator of traffic efficiency. The maximum theoretical bandwidth is very tightly correlated to the capability of the link. It would improve QoS by switching to a network with better conditions and higher performance.

\section{Security level}

Within a security profile, the security level is information that is used to define if data can be transmitted through another network. There will be a higher encrypted network scheme chosen.

\section{Cost of service}

Service cost can significantly vary from one internet service provider to another provider but in a different network environment.
It also has a close relationship with the available bandwidth and QoS levels. This can affect the user decision on which network to choose in a heterogeneous networking environment.

\section{E. Handover Latency}

The time span between the transmission or reception of its last IP packet through the previous access router and the first packet from the new access router is called handover latency. Handover latency plays a very important role in interactive cellular applications which could be notably dissimilar between different technologies.

\section{F. Power Utilization}

When the mobile terminal battery is running low, it becomes critical. In this kind of situation, a handover should focus on the power saving network to help prolong the life of the battery.

\section{G. Network Connection Time}

This is a time for the mobile terminal to stay connected to the particular network. Predicting network connection time is essential for opting the next handover initiation and maintaining QoS at a satisfactory level. If a handover happens too rapidly, it can result in network resources being wasted and handover failure.

\section{H. User Personal Preference}

Users can select a preferable network over the other candidate network for certain network access.

\section{VERTICAL HANDOVER DECISION MAKING ALGORITHMS}

An analysis of various vertical handover decision making (VHD) algorithms is discussed in this section. We categorized the handover algorithms into three categories which are RSS-based, multi-attribute based and combination-based handover schemes.

\section{A. RSS Based Handover Scheme}

Dwell Timer based Handover Decision Making Scheme: The handover decision scheme proposed by [7] and [8] predicts the travelling distance in a WLAN cell coverage area based on the variation of RSS values. Figure 8 shows the handover scheme that uses the travelling distance prediction technique. 


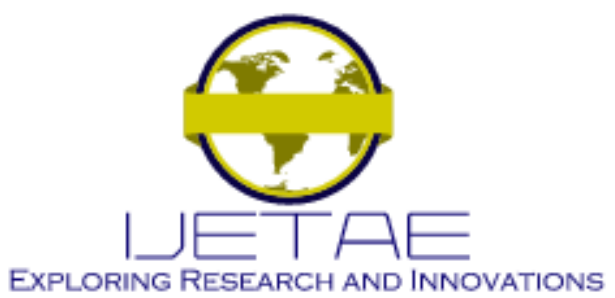

International Journal of Emerging Technology and Advanced Engineering

Website: www.ijetae.com (E-ISSN 2250-2459, Scopus Indexed, ISO 9001:2008 Certified Journal, Volume 12, Issue 01, January 2022)

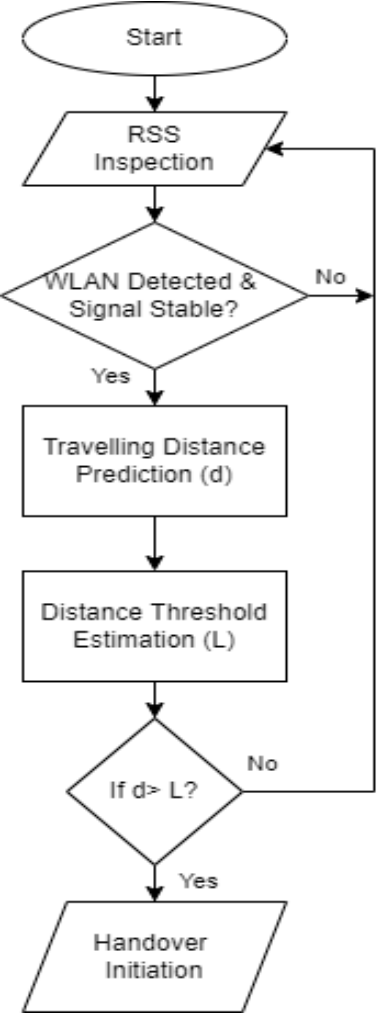

Figure 8 Flowchart of Travelling Distance Prediction based handover scheme [7]

The relationship between the RSS and the distance between the AP and MT at point $p$ inside the WLAN coverage area can be calculated by using the path loss model in Equation (1).

$$
R S S_{p}=E_{t} l_{O P}^{-\beta} 10^{\frac{\xi}{10}}
$$

where $E_{t}$ is the transmit power of the AP, $\beta$ is the path loss exponent and $\xi$ is a Gaussian distributed random variable with a mean of zero and a standard deviation up to $12 \mathrm{~dB} . l_{O P}$ represents the distance between point $p$ and the AP. The advantage of this approach is that it reduces the handover failure rate as MT travels at the speed of $30 \mathrm{~km} / \mathrm{h}$ and above. The main drawback of this work is the authors assumed that the MT travels in uniform velocity in the WLAN coverage.

Hussain et al. [8] proposed a handover necessity estimation (HNE) algorithm to minimize the number of handover failures and unnecessary handover while MT traverses a WLAN cell. It presented a new model for estimating dwell time in WLAN cells.
The RSS values at points $P_{1}$ and $P_{2}$ (as shown in Figure 9) are obtained to predict the dwell time in a WLAN cell. $P_{i}$ and $P_{o}$ in Figure 9 denote the point where the MT enter and exit from the WLAN cell, respectively. The algorithm has preserved both the handover failure and unnecessary handover rates at the desired level. Figure 10 shows the flowchart of the HNE method. However, the scheme showed that the unnecessary handover and handover failure rate increased as the speed of MT increased.

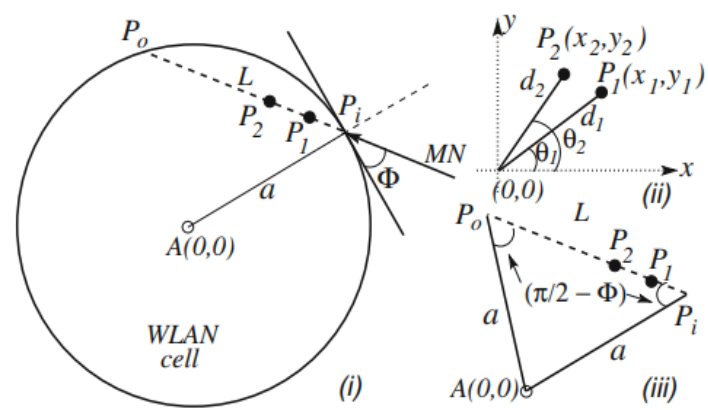

Figure 9 VHD geometrical mode

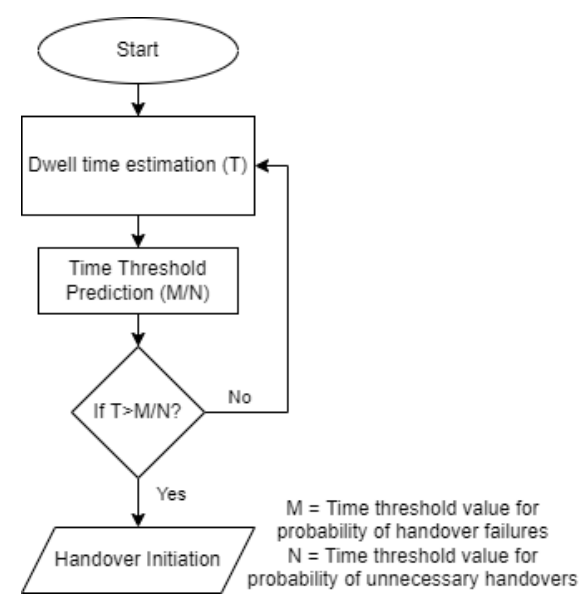

Figure 10 Flow Chart of Handover necessity estimation (HNE) method

Mahmood et al. [9] proposed a new handover mechanism to improve the imperfections of the handover schemes presented by [7] and [8]. The proposed mechanism estimates handover necessity by predicting the dwell time using consecutive RSS measurements in WLAN cells. The algorithm assumes that the WLAN cell has a circular contour and the mobile terminal traverses the WLAN cell at uniform velocity and straight line. The dwell time prediction scheme formula is shown as Equation (2). 


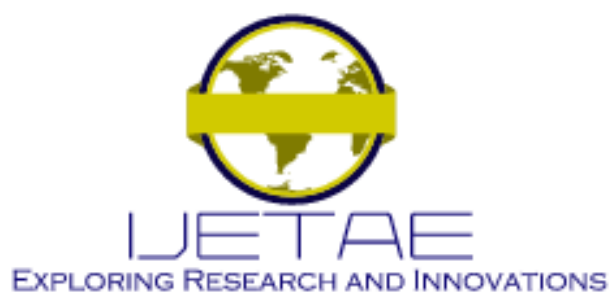

International Journal of Emerging Technology and Advanced Engineering

Website: www.ijetae.com (E-ISSN 2250-2459, Scopus Indexed, ISO 9001:2008 Certified Journal, Volume 12, Issue 01, January 2022)

$$
t_{n}=\frac{R^{2}-l_{C Z n}^{2}+v^{2}\left(t_{Z n}-t_{A}\right)^{2}}{v^{2}\left(t_{Z n}-t_{A}\right)}
$$

where $t_{n}$ denotes the dwell time of the network, $l_{C Z n}$ is the distance of entrance point $\mathrm{A}$ and the central point $\mathrm{M}$. $t_{Z n}$ and $t_{A}$ is the sampling time at point $Z_{n}$ and entry point $\mathrm{A}$, respectively. $v$ denotes the velocity of MT. Figure 11 shows the dwell time prediction scenario in the WLAN cell. It is presumed that the mobile terminal receives a considerably strong signal at point $\mathrm{A}$, while signal strength lowers from point B. Point $M$ is the middle point of the MT travelling path.

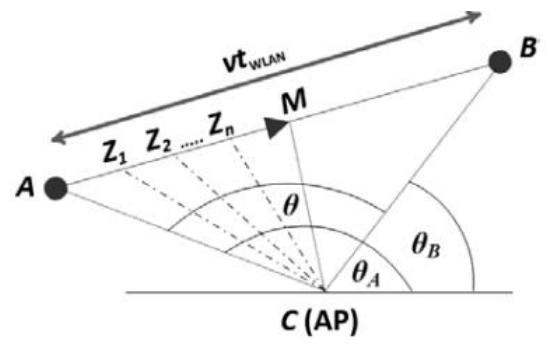

Figure 11 Travelling Time Prediction Scenario in a WLAN Cell

Though the mathematical expression proposed by [9] and [8] is nearly similar. The simulation results show that the number of unnecessary handovers can be kept at the desired level. The total number of unnecessary handovers is lower with an increase in MT velocity compared to [7] and [8] mechanisms. However, this scheme has a limitation where authors assume that MT moves at a constant velocity. But, this limitation has been overcome by Yew et al. [10][11].

RSS Based Adaptive Hand-Off Management Scheme in Heterogeneous Networks: A handover decision making based on the type of network in which it currently resides and the one with which it attempts to handover by some predefined rules was proposed by [12]. The handover depends on a few factors such as the velocity of the MT, latency of the handover process, type of network the MT is currently using, type of network which MT is trying to initiate handover and the coverage size of the cellular network, WLAN or High-Performance Radio LAN (HIPERLAN) cell the MT is currently residing.
Figure 12 shows the handover scheme based on the RSS value where $\mathrm{x} 1$ is the distance between $\mathrm{MT}$ and Base Station 1 (BS1) and $\mathrm{x} 2$ is the distance between MT and Base Station 2 (BS2). When MT was moving toward the $\mathrm{BS} 2$, the BS1 RSS value decreased. The handover is initiated if the RSS value is less than the threshold value. Assume MT is initially connected to BS1 and trying to handover to a BS2. The handover will only initiate when the RSS of BS2 is greater than the threshold.

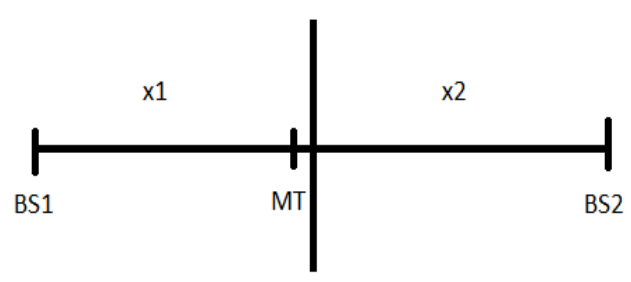

Figure 12 Handover scheme based on RSS value

MT is not initiating handover in this algorithm if the RSS value is lower than the RSS threshold level. The results of this scheme showed that the RSS threshold changes depending on network types and MT velocity. The thresold value is inversely proportional to the velocity of the MT. The drawback of this scheme is that the number of unnecessary handovers increases when the velocity of MT increases.

RSS based on link quality parameters for heterogeneous wireless networks: Ahjuha et al. [13] proposed a VHD algorithm that determines the best available wireless network while preserving the multimedia service quality of service (QoS) in heterogeneous wireless environments. The handover parameters used for the network selection are RSS, distance and outage probability. If the network has high average RSS values and the probability of outage is less than other networks, that network will be selected as a handover target. The flowchart of the handover algorithm is shown in Figure 13.

The algorithm improved the network selection with less overhead and burden on the mobile terminal compared to the conventional method. 


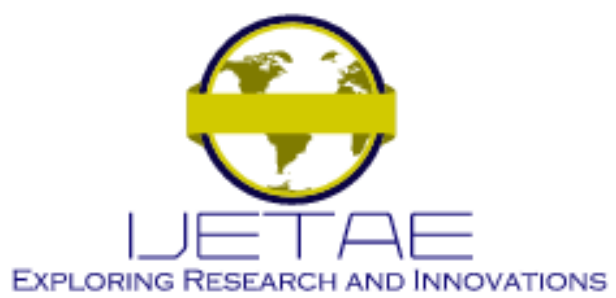

International Journal of Emerging Technology and Advanced Engineering Website: www.ijetae.com (E-ISSN 2250-2459, Scopus Indexed, ISO 9001:2008 Certified Journal, Volume 12, Issue 01, January 2022)

By using the outage probability and averaged RSS in the overlapped region of the heterogeneous environment, the efficiency of the handover has improved. It fulfilled the need for a decision on network selection that introspects the requirements of the application and retains the dynamic connection during the handover by engaging the makebefore-break approach. However, this scheme only focused on $2 \mathrm{G}$ and $3 \mathrm{G}$. The handover performance will degrade in the $5 \mathrm{G}$ network, especially in a high mobility scenario because $5 \mathrm{G}$ cell is much smaller than preceding networks.

\section{B. Multi-Attribute based Handover Scheme}

Multi-attribute-based handover scheme in Telemedicine: Bhat et al. [14] proposed a Dynamic Media Selection (DMS) based handover algorithm between WiFi and LTE in telemedicine scenarios. The DMS algorithm showed the best use of the channel to efficiently transmit the biosignal by offloading the procedure between WiFi and LTE. This optimal media selection is a quick process that remains active until the source reaches the destination. The RSS and SNR parameter values were measured and compared with their threshold values. This algorithm works for the always best connection provision of service. The RSS value of each network can be obtained by using Equation (3).

$$
\text { RSS }=\text { Transmit power }+ \text { Antenna gain }- \text { Path loss }
$$

The results demonstrate that both network $\mathrm{WiFi}$ and LTE with different node densities have reduced the delay in transmitting the packets from the source to the destination. In addition, with the increase of nodes, the throughput decreases.

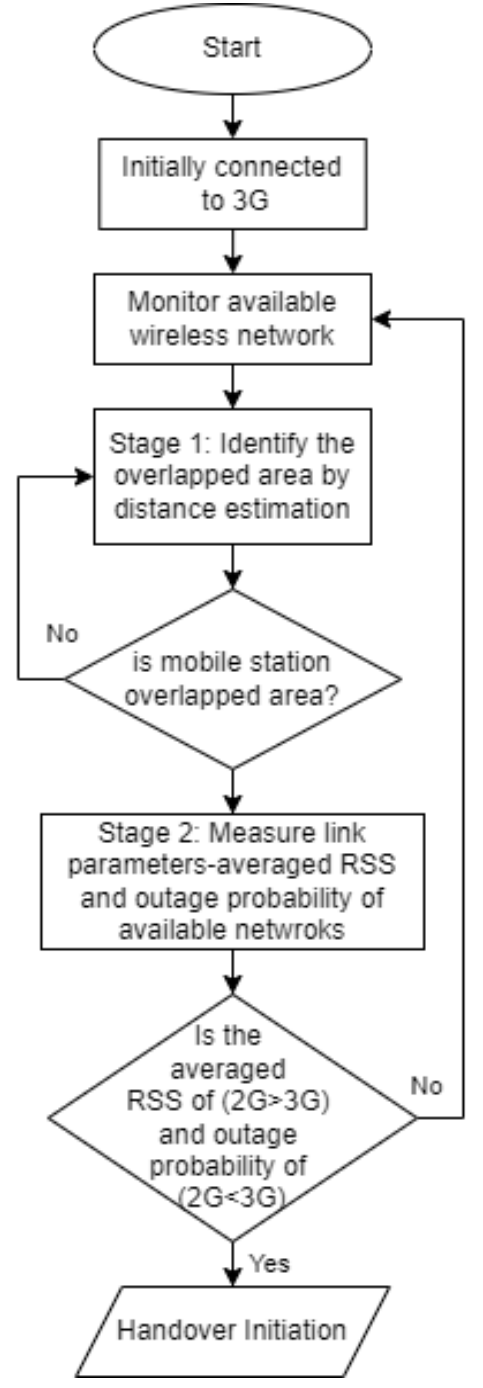

Figure 13 Handover algorithm proposed in [13] 


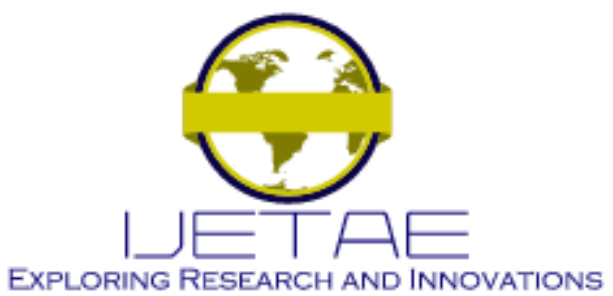

International Journal of Emerging Technology and Advanced Engineering Website: www.ijetae.com (E-ISSN 2250-2459, Scopus Indexed, ISO 9001:2008 Certified Journal, Volume 12, Issue 01, January 2022)

Mukhopadhyay et al. [15] proposed a multi-attribute based algorithm to improve the algorithm presented in [14]. The LTE and WiFi wireless technologies are considered in the proposed scenario. The handover parameters used in this algorithm contains RSS, SNR, power consumption, delay, bandwidth. The authors assumed only the LTE network is available in rural areas. The mobile terminal uses the LTE network to transfer data from rural area. If both WiFi and LTE are available, the mobile terminal will select the network with the highest Network Quality Value (NQV), where the NQV value can be obtained using Equation (4). If the $\mathrm{WiFi}$ is not available, the mobile terminal will continue with LTE.

$$
N Q V=\sum n_{i j}
$$

where $n_{i j}$ is the normalized value of each attribute. The algorithm aims to provide constant data transmission. Unfortunately, this algorithm does not take the MT velocity into account and it will lead to high unnecessary handover in 5G small cell networks, especially in wireless mobile communication environments. Figure 14 shows the flowchart of this algorithm.

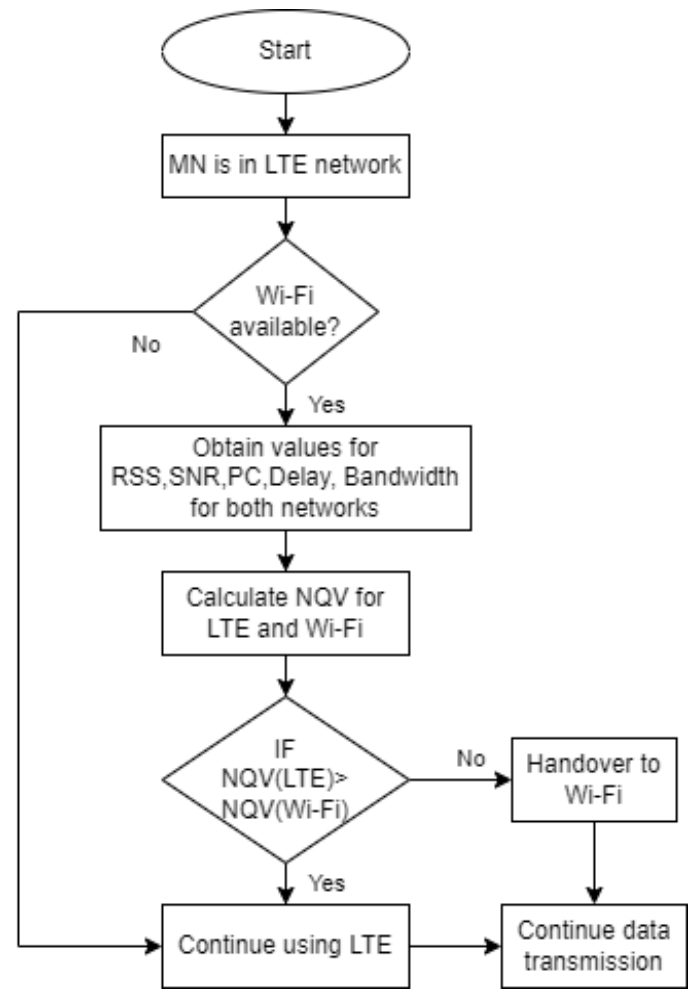

Figure 14 Multi-Attribute based handover scheme in Telemedicine
Yew et al. [16] proposed a telemedicine-based handover decision making (THODM) algorithm that transfers the patient health data to the healthcare centre by selecting the best wireless network based on the user preference, service requirements and speedometer. Parameters used in this algorithm were RSS, SNR, data rate, cost, and MT velocity. The speedometer is used to obtain the MT velocity. The THODM algorithm applied the dwell time prediction scheme, Equation (5), to estimate the dwell time in the small cell networks.

$$
T=\frac{R^{2}-r^{2}-d^{2}}{d v}
$$

where $R$ denotes the radius of the AP, $r$ is the radius of AP and Predefined RSS threshold. $d$ represents MT travelling distance from the boundary of AP coverage and predefined RSS threshold line. $v$ is the velocity of the MT.

The predefined dwell time threshold is set to 2 seconds. If the predicted dwell time, $T$, for MT to traverse the network is less than 2 seconds, the network will be rejected, and no handover will be initiated. Only the networks with the estimated dwell time greater than the threshold will be proceeded for network quality evaluation and ranked. Figure 15 shows the scenario of MT traversing the small cell network and Figure 16 shows the flowchart of the THODM scheme. The network candidate with the highest score will be selected as a handover target. The best network can be obtained by using Equation (6), where $Q_{k}$ is the quality function of each network candidate and $B$ is the best network to initiate handover.

$$
B=\max \left(Q_{k}\right)
$$

The algorithm proposed by the authors has reduced the unnecessary handover rate in a high-speed environment. This algorithm is more cost effective and provides higher throughput than the conventional handover schemes. 


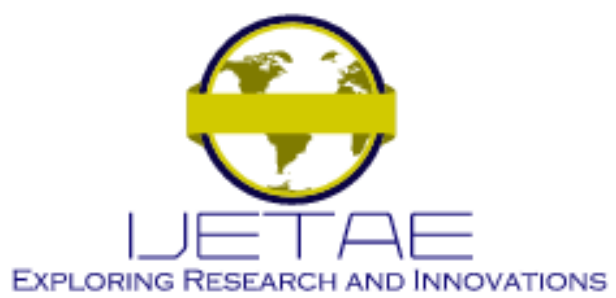

International Journal of Emerging Technology and Advanced Engineering Website: www.ijetae.com (E-ISSN 2250-2459, Scopus Indexed, ISO 9001:2008 Certified Journal, Volume 12, Issue 01, January 2022)

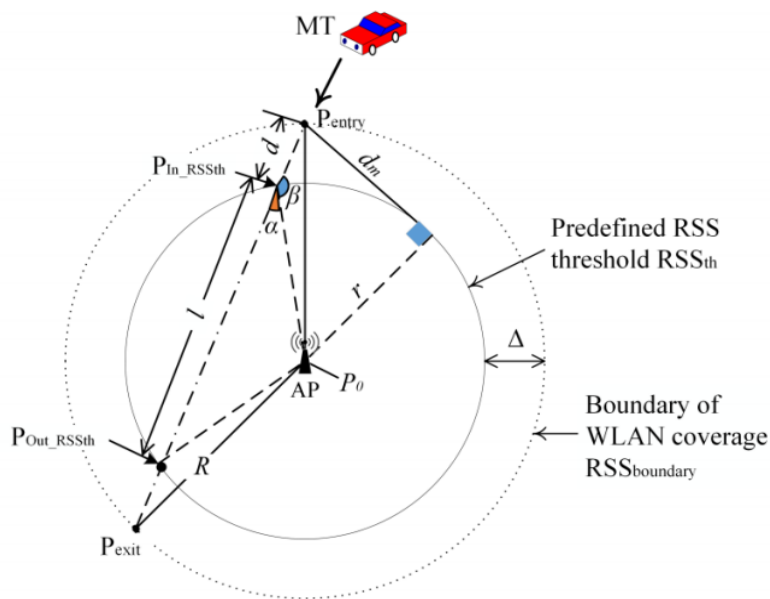

Figure 15 MT trajectory within small cell network

Yew et al. [17] proposed an Improved-TOPSIS (ITOPSIS) based handover for telemedicine applications. TOPSIS approach is used because of its multi-attribute decision analysis method that simultaneously estimates both the best and worst alternatives. Network-based handover criteria chosen for this algorithm are divided into two categories: QoS-based and non-QoS based. QoS based criteria consist of delay, throughput, and packet error rate, while the non-QoS based criteria are power usage and cost. The I-TOPSIS handover algorithm reacts differently toward the patient health conditions. The algorithm will ignore the user setting and priorities the high-quality network to enhance the service quality while the patient is in critical situations. The weight allocation for QoS based criteria can be calculated by Equation (7).

$$
W_{j}=\frac{\left(w_{j}^{*}\right)^{H}}{n^{h}}
$$

where $w_{j}^{*}$ denotes the assigned weight by the user to criterion $j . H$ denotes patient health condition in binary where one (1) stand for patients in non-critical condition and zero ( 0 ) represents a critical condition. $n$ denotes the number of QoS based criteria and $h$ represents the complement of $H$. Figure 17 shows the general flowchart of the I-TOPSIS handover algorithm. The weight of the nonQoS based criteria can be obtained by using Equation (8).

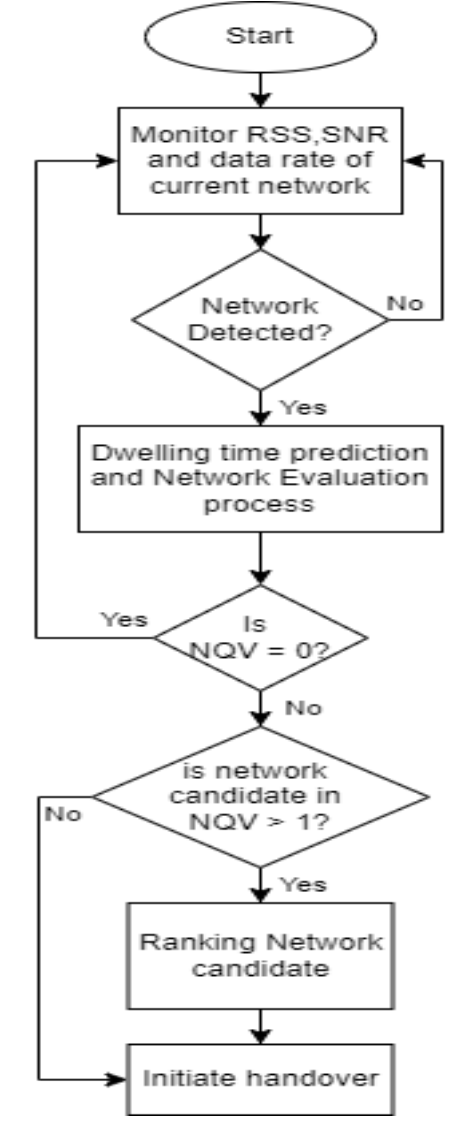

Figure 16 Flowchart of THODM scheme

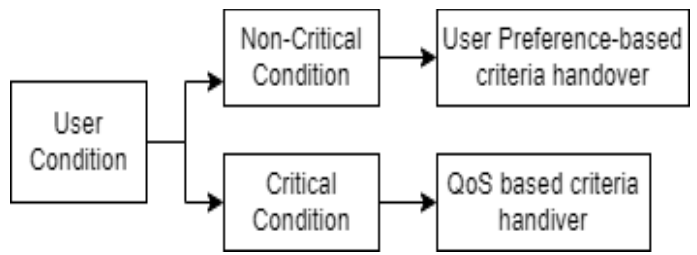

Figure 17 Network selection based on user health conditions [17]

$$
W_{j}=\mathrm{H} w_{j}^{*}
$$

The proposed algorithm has improved user satisfaction. The algorithm can be further improved by combining the prediction algorithm proposed in [10] to reduce the unnecessary handover in high dense $5 \mathrm{G}$ networks. 


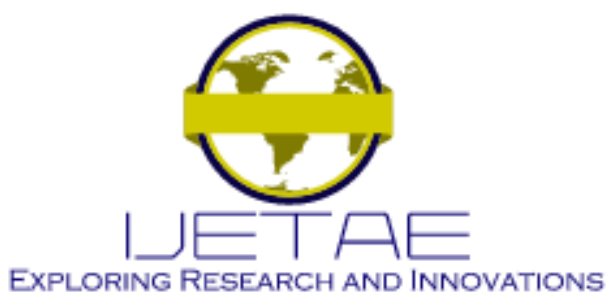

International Journal of Emerging Technology and Advanced Engineering

Website: www.ijetae.com (E-ISSN 2250-2459, Scopus Indexed, ISO 9001:2008 Certified Journal, Volume 12, Issue 01, January 2022)

\section{Combination based Handover Scheme}

Yew et al. [18] proposed a Robust and Fast Vertical Handover (RFVHO) algorithm for Telecardiology application that aims to always connect to the best network candidate in heterogeneous wireless networks. MIH is used for the interoperability between heterogeneous networks. $\mathrm{MIH}$ enables handover in heterogeneous networks with no perceptible interruption to an ongoing video or voice conversation. The algorithm searches for all available networks when the RSS of the serving network falls below the predefined threshold value. This algorithm uses Fuzzy Logic to select the most appropriate network among the available network candidates. MT monitors the RSS, velocity and user bandwidth requirement as shown in Table 1 regularly to ensure no handover is performed while the current network is still appropriate to the user requirement. The network quality, $Q_{k}$, can be evaluated by using Equation (9).

$$
Q_{k}=F\left(R S S_{k}-R S S_{T k}\right) \times F\left(B_{k}-B_{r e q}\right) \times F\left(V_{k}-V_{M T}\right)
$$

where $R S S_{k}$ is the RSS of network $k, R S S_{T k}$ denotes the threshold for network $k, B_{k}$ is the bandwidth of network $k, B_{r e q}$ is the user bandwidth requirement, $V_{M T}$ denotes MT velocity and $V_{k}$ is the maximum velocity support by network $k$. Network $k$ can be WLAN, UMTS or WiMAX.

TABLE 1

BANDWIDTH REQUIREMENT FOR TELECARDIOLOGY

\begin{tabular}{|c|c|}
\hline Services & Bandwidth \\
\hline Video & $640-5000 \mathrm{kbps}$ \\
\hline Audio & $32-256 \mathrm{kbps}$ \\
ECG & $24 \mathrm{kbps} / 12 \mathrm{leads}$ \\
Vital Signs & $2-5 \mathrm{kbps}$ \\
\hline
\end{tabular}

This algorithm showed a lower handover rate and no ping-pong effect or unnecessary handover occurred. The RFVHO algorithm can select the most appropriate network quickly and robustly. However, the authors only consider MT moving at a constant velocity of $20 \mathrm{~m} / \mathrm{s}$. The handover parameters such as security and cost can be considered in this work to further improve user satisfaction.

Ben et al. [19] proposed three different Fuzzy based handover algorithms: Fuzzy-SAW, Fuzzy-TOPSIS and Fuzzy-VIKOR. In dealing with imprecise data and numerous handover criteria, these algorithms harness the strength of Fuzzy Logic and multi-attribute decision making (MADM) method for intelligent decision making.
The handover parameters used for handover decision making are RSS, delay, MT velocity, data rate, and power.

The Simple Additive Weighting (SAW) method is the simplest MADM method used for decision making. Equation (10) is the SAW formula used to obtain the overall score by computing the sum of all weighted attribute values.

$$
C_{S A W i}=\sum_{j=1}^{n} a_{i j} w_{j}
$$

where $n$ is the number of context criteria, $a_{i j}$ is context criteria $j$ of the candidate network $i$ and $w_{j}$ is the weight of criteria $j$.

TOPSIS is widely used in the MADM process. An ideal solution can be calculated using Equation (11).

$$
C_{\text {TOPSISi }}=\frac{d_{i}^{-}}{d_{i}^{+}+d_{i}^{-}}
$$

where $d_{i}^{+}$and $d_{i}^{-}$denote the positive and negative ideal solutions of network candidates, respectively.

VIKOR is a method of MADM used to evaluate the best solution for different attributes. The concept is to provide the best solution to a given problem by computer utilities and alternative measures of regret. The $C_{V I K O R}$ can be obtained using Equation (12).

$$
C_{V I K O R i}=\arg \operatorname{Min}_{i \varepsilon m} \vartheta\left[\frac{s_{i}-\min S_{i}}{\max S_{i}-\min S_{i}}\right]+(1-\vartheta)\left[\frac{R_{i}-\min R_{i}}{\max R_{i}-\min R_{i}}\right]
$$

where $\vartheta$ represents the weight of the maximum group utility $(0.5), S_{i}$ denotes the utility measurement and $R_{i}$ represents the regret measurement computed.

The algorithms are simulated in a multi-radio access terminal environment. All these three algorithms reduce the decision delays. However, the authors assumed MT remains at a constant speed while traversing the networks.

Mathonsi et al. [20] proposed an intelligent based intersystem handover algorithm by incorporating grey prediction theory (GPT), Fuzzy Analytic Hierarchy Process (FAHP) and Principal Component Analysis (PCA), which aims to lower the handover latency. GPT is used to estimate the proper handover time by predicting the RSS value. The RSS prediction formula is expressed as Equation (13).

$$
\operatorname{PRSS}^{0}=(n+1)=\left(\operatorname{RSS}^{0}(1)-\frac{b}{c}\right) e^{-c n}\left(1-e^{c}\right)
$$

where $c$ is the development grey number and $b$ are the internal control grey number. $R S S^{0}$ is the received signal strength of the network. 


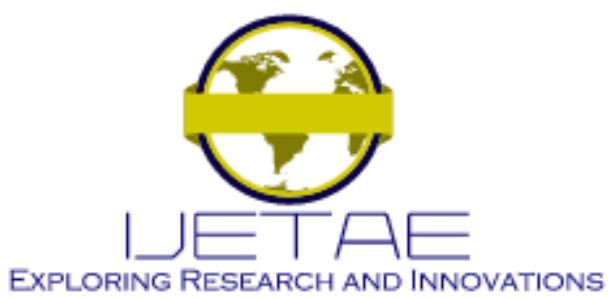

International Journal of Emerging Technology and Advanced Engineering

Website: www.ijetae.com (E-ISSN 2250-2459, Scopus Indexed, ISO 9001:2008 Certified Journal, Volume 12, Issue 01, January 2022)

Intersystem handover is initiated if the serving base station (SBS) RSS level is below the threshold and the target base station (TBS) predicted received signal strength (PRSS) level is greater than the SBS level.

The FAHP and PCA can reduce the inaccurate network selection and the handover algorithm becomes more adaptive to user preferences. PCA acquires the QoS factor by processing the weighted decision matrix and the network with the highest QoS factor will become the handover target. The QoS factor can be determined using Equation (14).

$$
Q o S_{k}=\frac{\sum_{i=1}^{k} \lambda_{k}}{\sum_{j=1}^{m} \lambda_{m}}
$$

where $k$ is a linearly independent principal component used to replace the $m$ original attributes and $\lambda_{k}$ is the eigenvalues of the covariance matrix.

Almutari et al. [21] proposed a Genetic algorithm (GA) based handover scheme. In many fields of science and engineering, GA has been adapted effectively for many applications. These algorithms can be used to solve different types of optimization problems, depending on the principles of natural selection and genetics. The GA solution is to address the issue of weight optimization to minimize rating abnormalities in vertical handover applications. The process can be divided into five steps as shown in Figure 18. This algorithm has successfully reduced the rating abnormality for SAW by $24.5 \%$ and TOPSIS by $32.5 \%$.

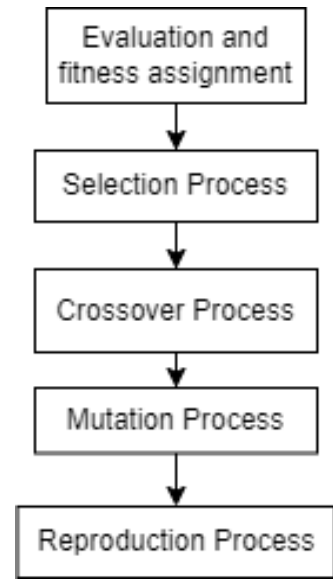

Figure 18 Genetic Algorithm process
Chattate et al. [22] proposed a Fuzzy Enhanced-TOPSIS based handover decision-making algorithm that considers each access network throughput, data rate, jitter, latency, and battery. The Fuzzy Enhanced-TOPSIS (FE-TOPSIS) method first construct a decision matrix where each row $i$ corresponds to an available network $\left(\mathrm{A}_{1}, \mathrm{~A}_{2}, \mathrm{~A}_{3} \ldots\right)$ and each column $j$ corresponds to a different criterion $\left(C_{1}, C_{2}\right.$, $\left.\mathrm{C}_{3} \ldots\right)$. Then, assign the weight fitting to each criterion by using the Fuzzy analytic hierarchy process (FAHP) method. After that, calculate the performance of each network by using the Fuzzy Enhanced-TOPSIS algorithm and rank the alternatives by sorting the value of relative closeness, $C_{i}$, in descending order. The value of relative closeness to the ideal solution is expressed in Equation (15), where $\mu_{1}$ and $\mu_{2}$ are relative importance. $S_{i}^{+}$and $S_{i}^{-}$ refer to the distance of each alternative from the ideal positive solution (FPIS) and ideal negative solution (FNIS).

$$
C_{i}^{\text {Proposed }}=1-\frac{\mu_{1} * S_{i}^{+}+\mu_{2} * S_{i}^{-}}{S_{i}^{+}+S_{i}^{-}}, i=1, \ldots, n
$$

In this method, the authors managed to reduce the number of handovers compared to the Fuzzy-TOPSIS algorithm. In addition, this FE-TOPSIS approach is capable of evaluating the best network with a lower handover latency.

Tan et al. [23] proposed a Multi-Attribute and Neural Network Handover Algorithm for heterogeneous networks with UMTS, GPRS, WLAN, 4G and 5G. Every network has neural network models of its three-layer Back Propagation (BP). Each layer's neuron weight is determined by the values of maximum transmission rate, minimum delay, SINR, bit error rate, user moving speed, packet loss and download rate of the network. MT gathers all the weights and inputs the values to the five respective qualified neural network models. The forecast values of the network download rates are obtained for each of the five network types and the network with the highest score is chosen as the target handover network. Figure 19 shows the flow diagram of the implementation of the handover scheme. The results show that the switching times increase when the download rate of the network drops. 


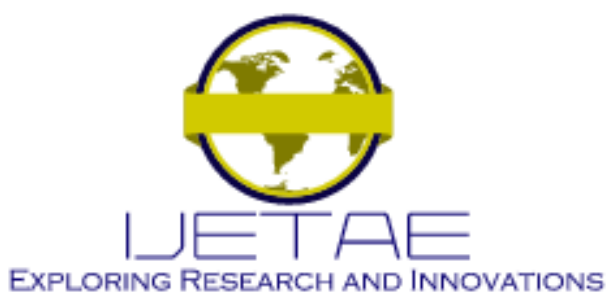

International Journal of Emerging Technology and Advanced Engineering

Website: www.ijetae.com (E-ISSN 2250-2459, Scopus Indexed, ISO 9001:2008 Certified Journal, Volume 12, Issue 01, January 2022)

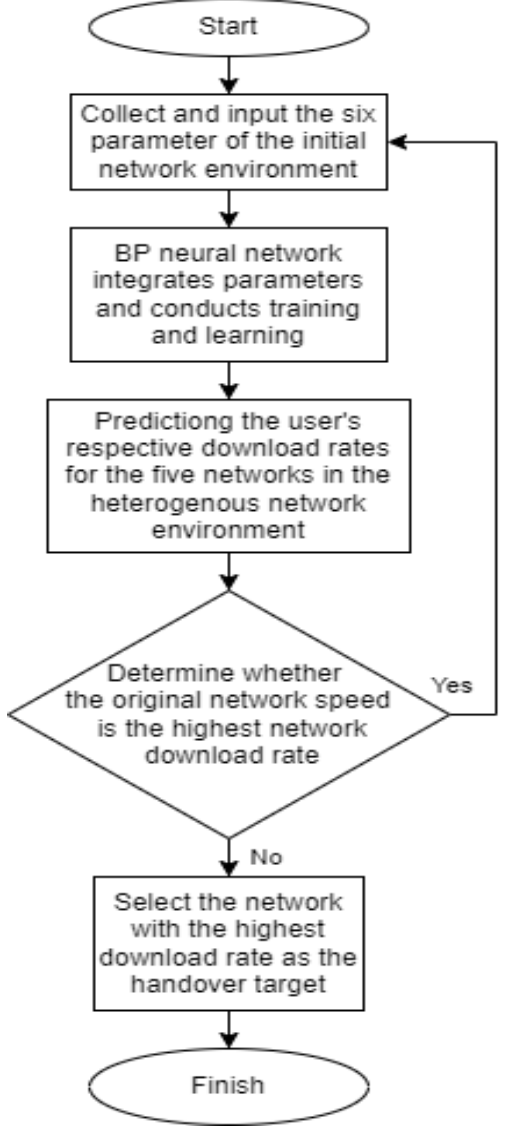

Figure 19 Flow diagram of the Multi-Attribute and Neural Network

Dipha et al. [24] presented an algorithm that is a nopairing authentication mechanism and provides users on the wireless network with security and privacy. This mechanism consists of two primary steps, the predeployment phase and the authentication phase. The predeployment phase initializes and creates an initial architecture for possible handover and authentication procedures. The initialization process is carried out by the authentication server (AS). In the handover authentication phase, MT initiates the vertical handover process if the network does not accept the user's request. Mutual authentication is obtained between the MT and new connection point. It is possible to release and build a peerto-peer transient key directly upon authorization.

Several e-health users and a set of cellular networks defined as critical and non-critical conditions for remote health monitoring of cardiac patients are considered in this algorithm.
The state of network traffic, such as direct storage and real-time, would be selected based on the circumstances. Medical information is collected from patients and then transmitted to the medical facility over a wireless network such as WiFi, UMTS, and WiMAX. The user health condition is considered as one of the metrics in this scheme. The algorithm monitors the serving network quality and user moving speed on a regular basis. When the serving network cannot meet the service requirements, the Trust and Privacy Multiple Attribute Vertical Transfer algorithm (TPMVHO) searches for nearby available networks that meet user requirements. The parameters weight value is determined based on the user health condition.

The hybrid genetic metaheuristic with cuckoo search (GA-CS) algorithm increases the performance efficiency and has greater flexibility to resolve larger-scale problems to find optimum attribute weight values. The Intuitionistic Fuzzy TOPSIS algorithm ranks the alternative networks with the obtained weight values. This approach is capable of reducing delays by spreading computational activities across the accessible visitor network. The algorithm has reduced the number of handovers by $25.3 \%$. This algorithm can also minimize abnormal ranking problems in the TOPSIS method and ensure a smooth and seamless connection. This algorithm can be further improved by considering cost and power consumption as input parameters to increase user satisfaction.

Diong et al. [25] presented a Fuzzy-TOPSIS based handover algorithm. The fuzzy approach is used to overcome the limitation of MADM, which cannot process uncertain and imprecise data within criteria. This algorithm combines the advantages of both algorithms, which are multi-criteria based, process uncertain input data and weight value to obtain the optimal decision. The Fuzzy AHP approach is implemented to process the parameters weight value and parameters for TOPSIS. The parameters used in this algorithm consist of RSS, bit error rate, SNR, cost, delay, packet loss and data rate.

Firstly, the Fuzzy-TOPSIS handover algorithm builds a decision matrix for each network candidate concerning its criteria. Next, the weight value is obtained by using Equation (16).

$$
w_{i}=\left(\frac{l+m+u}{3}\right)
$$

where $l, m$ and $u$ denotes the lower bound value, midvalue and upper bound of the triangular fuzzy number based on Satty's AHP scale. 


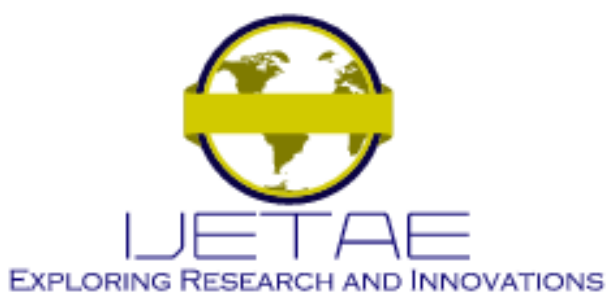

International Journal of Emerging Technology and Advanced Engineering

Website: www.ijetae.com (E-ISSN 2250-2459, Scopus Indexed, ISO 9001:2008 Certified Journal, Volume 12, Issue 01, January 2022)

Weight values are set based on the user preference using linguistic terms. After that, the TOPSIS algorithm transforms different scales and units among various criteria into common measurable units to allow comparisons across all the criteria. Lastly, Equation (11) is used to calculate the relative closeness of each network to find the best network for handover. This algorithm is able to minimize unnecessary handover and ping-pong effects effectively.

\section{SUMMARY OF OVERALL VHD SCHEMES}

Table II summarise the strengths and weaknesses of the reviewed VHD schemes.

TABLE II

SUMMARY OF VHD SCHEMES

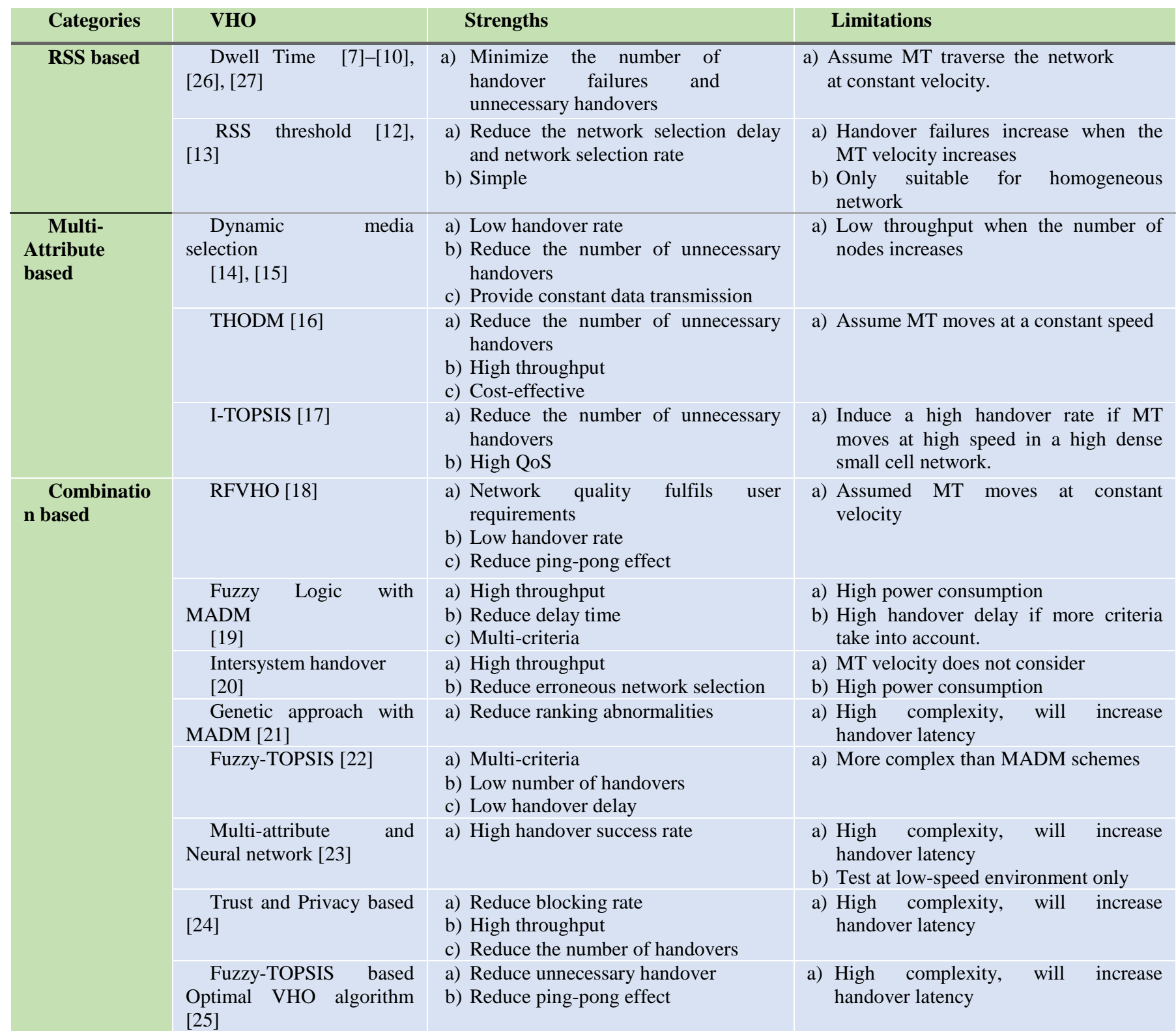




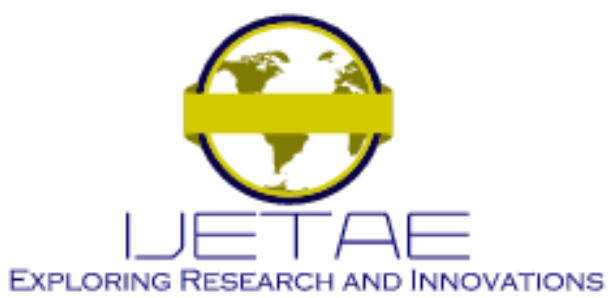

\section{International Journal of Emerging Technology and Advanced Engineering}

Website: www.ijetae.com (E-ISSN 2250-2459, Scopus Indexed, ISO 9001:2008 Certified Journal, Volume 12, Issue 01, January 2022)

\section{CONCLUSION}

Due to rapid progressions in network technologies, more efforts are needed to get seamless connections such as live stream, transfer big data, and cloud services. In this paper, we reviewed various vertical handover decision-making algorithms. The vertical handover decision making algorithms are categorized into three groups and analyzed their strengths and weaknesses in terms of criteria, complexity, and selection methodology. This research field has been used in several commodities and field tests for extended over a long time now. However, truly achieving the seamless connection has not yet been placed in daily life even though this study has been here for so long.

The vertical handover algorithm is either insufficient use of network parameters or lacks the detail to be tested in real-environment situations to gain more studies. Therefore, this field of research is still a challenging area and open issue. The most difficult part is formulating a handover algorithm that can be used in a high dense $5 \mathrm{G}$ network. High dense 5G network is more challenging than preceding networks because its cell coverage is much smaller.

In the future, the internet is getting more evolved to be used and more applications are needed to learn more about network conditions to work correctly and efficiently alongside seamless connectivity. Therefore, a common infrastructure is needed to achieve seamless handover.

\section{Acknowledgement}

This research is supported by the Ministry of Higher Education (Kementerian Pengajian Tinggi) Malaysia, Fundamental Research Grant Scheme FRGS/1/2020/TK0/UMS/02/2, Universiti Malaysia Sabah Grant SGI0113-2020 and SGI0138-2020.

\section{REFERENCES}

[1] I. Chattate, J. Bakkoury, A. Khiat, and M. El Khaili, "Overview on technology of vertical handover and MIH architecture," Colloq. Inf. Sci. Technol. Cist, vol. 0, pp. 31-34, 2016.

[2] L. Chen et al., "A Smart Decision Model for Vertical Handoff," ANWIRE Int. Work. Wirel. Internet Reconfigurability, no. May 2014, pp. 1-5, 2004.

[3] Z. Becvar, J. Zelenka, and R. Bestak, "Comparison of Handovers in Umts and Wimax," Architecture, no. May, pp. 2-5, 2014.

[4] E. Popovici, O. Fratu, A. Vulpe, and S. Halunga, "New developments in vertical handover based on media independent handover standard," Wirel. Pers. Commun., vol. 78, no. 3, pp. 1739 1753, 2014.

[5] D. He, C. Chen, S. Chan, and J. Bu, "Analysis and improvement of a secure and efficient handover authentication for wireless networks," IEEE Commun. Lett., vol. 16, no. 8, pp. 1270-1273, 2012.
[6] K. R. Rao, Z. S. Bojkovic, and B. M. Bakmaz, Wireless Multimedia Communication Systems. CRC Press, 2017.

[7] X. Yan, N. Mani, and Y. A. Şekercioğlu, "A traveling distance prediction based method to minimize unnecessary handovers from cellular networks to WLANs," IEEE Commun. Lett., vol. 12, no. 1, pp. 14-16, 2008.

[8] R. Hussain, S. A. Malik, S. Abrar, R. A. Riaz, H. Ahmed, and S. A. Khan, "Vertical handover necessity estimation based on a new dwell time prediction model for minimizing unnecessary handovers to a WLAN cell," Wirel. Pers. Commun., vol. 71, no. 2, pp. 1217-1230, 2013.

[9] A. Mahmood, H. Zen, A. K. Othman, and S. A. Siddiqui, "A novel travelling time estimation mechanism for minimizing unnecessary handovers from cellular networks to WLANs," Proc. 2nd Int. Conf. Inf. Technol. Electron. Commer. ICITEC 2014, pp. 38-42, 2014.

[10] H. T. Yew, E. Supriyanto, M. H. Satria, and Y. W. Hau, "New vertical handover method to optimize utilization of wireless local area network in high-speed environment," PLoS One, vol. 11, no. 11, 2016.

[11] E. M. Malathy and V. Muthuswamy, "Knapsack - TOPSIS technique for vertical handover in heterogeneous wireless network," PLoS One, vol. 10, no. 8, pp. 1-16, 2015.

[12] D. Sarddar, S. Maity, A. Raha, R. Jana, U. Biswas, and M. K. Naskar, "A RSS Based Adaptive Hand-Off Management Scheme In Heterogeneous Networks,” Int. J. Comput. Sci. Issues, vol. 7, no. 6 , pp. 232-238, 2010.

[13] K. Ahuja, B. Singh, and R. Khanna, "Network selection algorithm based on link quality parameters for heterogeneous wireless networks," Opt., vol. 125, 2014.

[14] S. Bhat, A. Mukhopadhyay, and B. K. Sandhya Rani, "Dynamic media selection between WiFi and LTE in telemedicine scenarios," 2017 Int. Conf. Adv. Comput. Commun. Informatics, ICACCI 2017, vol. 2017-Janua, pp. 601-606, 2017.

[15] A. Mukhopadhyay, R. R. Hegde, and A. S. Thomas, "Handover mechanisms in wireless heterogeneous telemedicine networks," Proc. 3rd Int. Conf. Comput. Methodol. Commun. ICCMC 2019, pp. 938-945, 2019.

[16] H.-T. Yew, E. Supriyanto, M. Haikal, and Y.-W. Hau, "A Vertical Handover Management for Mobile Telemedicine System using Heterogeneous Wireless Networks,” Int. J. Adv. Comput. Sci. Appl., vol. 7, no. 7, pp. 1-9, 2016.

[17] H. T. Yew, C. S. Kheau, R. K. Y. Chin, A. Chekima, and M. H. Satria, "Improved-TOPSIS based handover scheme for telemedicine service using heterogeneous wireless networks," Proc. - 2017 IEEE 2nd Int. Conf. Autom. Control Intell. Syst. I2CACIS 2017, vol. 2017-Decem, no. October, pp. 155-160, 2017.

[18] H. T. Yew, Y. Aditya, H. Satrial, E. Supriyanto, and Y. W. Hau, "Telecardiology System for Fourth Generation Heterogeenous Wireless Networks," ARPN J. Eng. Appl. Sci., vol. 10, no. 2, pp. 600-607, 2015.

[19] A. Ben Zineb, M. Ayadi, and S. Tabbane, "An Enhanced Vertical Handover Based on Fuzzy Inference MADM Approach for Heterogeneous Networks," Arab. J. Sci. Eng., vol. 42, no. 8, pp. 3263-3274, 2017.

[20] T. E. Mathonsi, O. P. Kogeda, and T. O. Olwal, "Intersystem Handover Decision Model for Heterogeneous Wireless Networks," 2018 Open Innov. Conf. OI 2018, pp. 1-7, 2018. 


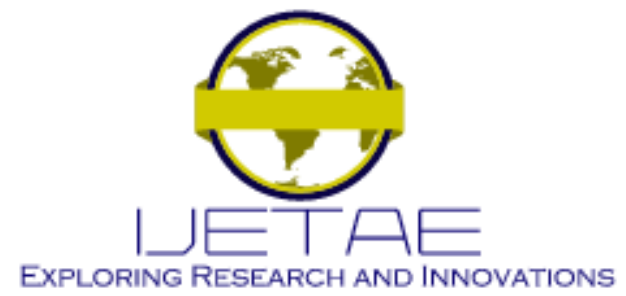

International Journal of Emerging Technology and Advanced Engineering

Website: www.jjetae.com (E-ISSN 2250-2459, Scopus Indexed, ISO 9001:2008 Certified Journal, Volume 12, Issue 01, January 2022)

[21] A. F. Almutairi, M. Hamed, M. A. Landolsi, and M. Algharabally, "A genetic algorithm approach for multi-attribute vertical handover decision making in wireless networks," Telecommun. Syst., vol. 68, no. 2, pp. 151-161, 2018.

[22] I. Chattate, M. E. L. Khaili, and J. Bakkoury, "A new fuzzy-topsis based algorithm for enhancing decision making in a heterogeneous network," J. Commun., vol. 14, no. 3, pp. 194-201, 2019.

[23] X. Tan, G. Chen, and H. Sun, "Vertical handover algorithm based on multi-attribute and neural network in heterogeneous integrated network," Eurasip J. Wirel. Commun. Netw., vol. 2020, no. 1, pp. 1$21,2020$.

[24] M. Dhipa, B. Kalaavathi, and A. Chandrasekar, "Trust and privacy based vertical handoff decision algorithm for telecardiology application in heterogeneous wireless networks," J. Ambient Intell. Humaniz. Comput., no. 0123456789, 2020.
[25] B. W. Diong, M. I. Goh, S. K. Chung, A. Chekima, and H. T. Yew, "Vertical Handover Algorithm For Telemedicine Application In 5g Heterogeneous Wireless Networks," Int. J. Adv. Comput. Sci. Appl., vol. 12, no. 8, pp. 611-617, 2021.

[26] S. K. Chung, M. I. Goh, H. T. Yew, B. L. Chua, S. S. Husain, and A. I. Mbulwa, "Enhanced Bandwidth Based Handover Decision Making Algorithm for Small Cell Wireless Networks," IEEE Int. Conf. Artif. Intell. Eng. Technol. IICAIET 2020, no. September, 2020.

[27] H. T. Yew, A. Chekima, A. Kiring, A. I. Mbulwa, J. A. Dargham, and S. K. Chung, "RSS Based Vertical Handover Schemes in Heterogeneous Wireless Networks: Past, Present Future," IEEE Int. Conf. Artif. Intell. Eng. Technol. IICAIET 2020, no. September, 2020. 